\title{
From notions of health to causality
}

\author{
Wim Dekkers · Bert Gordijn
}

Published online: 10 June 2009

(C) Springer Science+Business Media B.V. 2009

In 2005 the European Society for Philosophy of Medicine and Health Care (ESPMH) initiated an annual contest for young scholars. Every year an ESPMH prize is awarded to a scholar younger than 35 years of age for a scientific contribution on ethical, epistemological, or other philosophical topics relating to medicine and health care. The first paper in this issue, 'On the relationship between individual and population health', has been written by the winner of this prize in 2007, Onyebuchi A. Arah. Compared to the idea of individual health, 'population health' is a relatively new, rather fashionable term in the field of medicine and health care. The relationship between individual and population health is partially built on the dichotomization of medicine into clinical medicine and public health. Individual and population health are often seen as absolute and independent concepts. Onyebuchi A. Arah argues that the relationship between the two is largely relative and dynamic. His argument is based on an attempt to include a population perspective on health in definitions of health, particularly by emphasizing the role of the 'context' component of any notion of health.

The second contribution in this issue, written by Shawn H. E. Harmon, also deals with public health, but this paper is more practical in nature. After having reminded us of the fact that public health is a multidisciplinary and complex phenomenon, the author argues that public health promotion is a moral duty and that, although multiple actors are relevant and necessary to fulfilling this duty, the role of international actors is paramount. The paper especially focuses on one of the most important international

W. Dekkers $(\bowtie) \cdot$ B. Gordijn

UMC St Radboud Nijmegen, 114 IQ Healthcare, Section Ethics, PO Box 9101, 6500 Nijmegen, HB, The Netherlands

e-mail: w.dekkers@iq.umcn.nl organizations in this field, that is, the World Health Organization (WHO). Shawn H. E. Harmon argues that better health can and must be better promoted through a more robust interpretation of the WHO's role. Together with other international organizations, he argues, the WHO has not yet played its necessary part in promoting 'health for all'.

The third paper, written by Rui Nunes, Guilhermina Rego and Christina Brandao, leaves the difference between individual and public health for what it is. The authors evaluate the role of independent regulatory agencies in the field of health care, as compared to the role of traditional public regulations, with regard to a fair process of equal access to health care and of setting limits to health care. In their argument Norman Daniels' and James Sabin's theory of accountability for reasonableness plays a central role. The authors conclude that accountability for reasonableness should be regarded as a landmark of any health care reform. The rationale for limit-setting decisions must be clearly communicated toward the public.

Karin Dahlberg, Les Todres and Kathleen Galvin focus on individual health care. They critically review the common standard of 'patient-centred' or 'patient-led' health care and argue that current patient-led approaches hinder a focus on a deeper understanding of what patient-led care could be. Based on various phenomenological and existential insights they present an alternative interpretation of patient-led care which they call 'lifeworld-led care'. A philosophy of the person, a view of well-being, and a philosophy of care should be key elements in the further development of this 'lifeworld-led care'.

With the paper of Juha Räikkä, 'The ethical and political evaluation of biotechnology strategies', we enter a new category of topics in this issue, that is, regulatory aspects of research and new biotechnologies. Juha Räikkä focuses on 
the role and function of ethical advisory committees and other ethics bodies that are supposed to take care of the ethical dimension of biotechnology strategies. In his view, it is quite unproblematic that the work of ethics committees and other (semi-)governmental bodies concerns only a relatively narrow range of issues and does not directly concern all the social and economic realignments that accompany biotechnology. This plea for a more modest role and function of ethical advisory committees goes hand in hand with the view that ethics committees can definitely promote a public debate that can form the basis for societal and political decision making.

One of the new emerging biotechnologies is tissue engineering. Although human tissue donation-together with organ donation-has been normal practice for about four decades, nowadays there is a clear lack of ethical and legal guidelines. Michael Steinmann deals with the uncertainty and indistinctness in current propositions for the regulation of tissue donation. He mainly focuses on two recent German documents. Taking the autonomy of the donor as a starting point, he analyses a couple of ethical problems related to this notion. Because tissue engineering is a complex matter, truly 'informed' consent is hardly possible. However, also a kind of blanket consent is controversial from an ethical perspective, because it cannot be seen as an expression of self-determination. The author states that donors cannot be left alone with the task to control scientific research and to have their personal and property rights respected. Institutional support is needed.

The paper written by Marilys Guillemin and Kristin Heggen deals with the relationship between researcher and participant in qualitative research. It is based on the personal experience of one of the authors-in the role of researcher-with a woman suffering from chronic fatigue syndrome. The interview with this woman was an experience where the researcher was left uneasy and wondering whether she had done 'the right thing'. Through experiences as this one, the authors have come to understand the interactions between researcher and participant not just in terms of methodological integrity, but also to recognize them for their ethical significance. Paramount within qualitative research, they argue, is a need to balance establishing rapport and establishing rich relationships with participants while maintaining distance out of respect for participants' privacy. In their view, negotiating these zones of relations between researcher and participant is hard work.

The following contributions deal with three traditional medical-ethical problems: abortion, euthanasia and organ donation. Chris Kaposy defends the public funding of abortion in the Canadian health care system. He briefly presents an argument that characterizes abortion sought for social reasons as medically necessary care. $\mathrm{He}$ also presents a justice argument that shows that-even if abortion is not regarded as medically necessary care-the reasons that typically motivate women to seek abortion are sufficiently weighty from a moral perspective that it would be unjust to deny them public funding.

Joke Lemiengre et al. describe euthanasia policies of nursing homes in Flanders (Belgium) and the possible influence of religious affiliation on the content of policy documents. The method they used is a content analysis of euthanasia policy documents. Their study revealed that euthanasia requests from patients are seriously considered in euthanasia policies of nursing homes, with great attention for palliative care and interdisciplinary cooperation. More Catholic nursing homes compared to non-Catholic nursing homes did not permit euthanasia.

Kristin Zeiler deals with the problem of live organ donation with special attention to the gender-imbalance in emotionally related live kidney donation. In these cases of emotionally related live organ donation, female partners appear to donate significantly more often than male partners. The author argues for the benefit of the concept of 'just love' as an analytic tool in the analysis of emotionally related live donation, where the potential donor(s) and the recipient are engaged in a love relation. In her view, the analysis of loving live donations needs to acknowledge the specific features of such donation and that it is unsatisfactory to focus only on love in analyzing that which can take place in such relations. Love is just, she suggests, when it takes into account and affirms the concrete reality of the lover and the loved-one and when it implies neither the exploitation of the lover nor the domination of the beloved one.

This issue also contains two papers on causation and the way epidemiology can contribute to the philosophical debate. Not all data used by people interested in causal claims come from experiments that use at random assignments to control and treatment groups. A lot of research in the health sciences depends on non-experimental, observational data. One of the most important problems in the health sciences therefore concerns making warranted causal claims using data from observational research. Andrew Ward examines one method of warranting causal claims that is widespread in epidemiology, that is, the use of causal criteria. He argues that cases of complex causation generally, and redundant causation specifically, undermine the use of such criteria to warrant causal claims.

Leen de Vreese focuses on the philosophical basis and metaphysical presuppositions of the use of the notion of causation in epidemiology. The author argues that discussions of epidemiologists on causation are not always very enlightening with regard to the notion of cause. Epidemiologists seem to confuse the practical results of epidemiological research at the population level with the 
metaphysical view about the reality of disease causation at the individual level.

The last paper in this issue is in the field of the philosophy of health and disease. In the tradition of Canguilhem's Le normal et le pathologique, Maël Lemoine deals with the opposition between the healthy and the pathological. Although a strict dichotomy cannot be upheld based on our daily experiences, a clarification of the logical structure of this opposition might improve our insight in this crucial distinction. 